\title{
Sistem Pencatatan Data Penggunaan Air Berbasis Smartphone Android
}

\author{
http://dx.doi.org/10.28932/jutisi.v5i3.1901 \\ Heri Andrianto ${ }^{\bowtie \# 1}$, Kemal Hafidzar ${ }^{* 2}$ \\ \#1, *2 Program Studi Teknik Elektro, Universitas Kristen Maranatha \\ Jl. Surya Sumantri No.65, Bandung, Jawa Barat 40164 \\ ${ }^{1}$ heri.andrianto@eng. maranatha.edu \\ ${ }^{2}$ kemalhafidzar@gmail.com
}

\begin{abstract}
Currently, the recording of water usage is still done manually. A more practical and efficient recording system for water usage is needed. In this paper, a water meter data logger system has been designed. This system consists of a water meter device and a smartphone application. Communication between the water meter device and smartphone via a Wireless Fidelity (WiFi) connection. The water meter device uses the Wemos D1 Mini Module as a controller and a flow sensor to find out the amount of water used. Data received by the smartphone from the water meter device will be processed and entered into the smartphone database (SQLite). From the test results, the water meter device can calculate water usage with an average error of 0.2957 . Water usage data can be stored in a database on a smartphone. The distance of the wireless connection range between the water meter device and the smartphone is 37 meters without a barrier and 16 meters with a barrier.
\end{abstract}

Keywords - data logger; smartphone application; water meter device.

\section{Pendahuluan}

Saat ini proses pencatatan penggunaan air oleh petugas masih dilakukan secara manual, yaitu petugas mencatat penggunaan air yang ditunjukan pada meteran air konvensional di rumah-rumah pelanggan. Jika rumah sulit dijangkau dan pemilik rumah tidak ada di rumah, maka hal ini akan menyebabkan petugas tidak dapat memperoleh data penggunaan air yang tercatat pada meteran air [1]. Selain itu, permasalahan lain yang dapat terjadi yaitu kesalahan penulisan data penggunaan air [2] [3]. Pengukur penggunaan air diperlukan untuk memastikan pembacaan penggunaan air yang akurat [4]. Oleh karena itu, diperlukan sistem pencatatan data penggunaan air pintar yang lebih praktis, efektif dan efisien. Sistem pencatatan air pintar akan membuat pengguna lebih sadar akan penggunaan air dan membantu mereka mengurangi penggunaan air [5].
Penelitian-penelitian yang sudah dilakukan untuk merancang dan membangun sistem pencatatan data meteran air diantaranya yaitu Graha dkk merancang sistem proteksi kebocoran kran dan pencatatan meteran air digital berbasis Arduino Uno R3 [6]. Herdianto dkk, merancang sistem pengawasan data meteran air pelanggan PDAM berbasis mikrokontroler ATmega16 [7]. Yaddarabullah dan Dewi Lestari merancang sistem komunikasi data perangkat pencatat penggunaan air digital berbasis service-oriented architecture, dengan tujuan agar dapat mendukung multiplatform yang diaplikasikan pada alat pencatatan meter air PDAM [8]. Penelitian-penelitian sebelumnya tidak melaporkan sistem pencatatan data penggunaan air yang terdiri dari perangkat water meter dan smartphone Android.

\section{A. Rumusan Masalah}

Rumusan masalah pada penelitian ini berdasarkan latar belakang masalah diatas yaitu:

- Bagaimana merancang dan membuat perangkat pencatat penggunaan air berbasis Wemos D1 Mini?

- Bagaimana merancang dan merealisasikan aplikasi pada smartphone Android untuk menerima data dari perangkat pencatat penggunaan air melalui koneksi WiFi?

\section{B. Tujuan}

Merancang dan merealisasikan perangkat pencatat penggunaan air berbasis Wemos D1 Mini yang dapat mengirimkan data ke aplikasi di smartphone Android melalui koneksi WiFi.

Pada penelitian ini, sistem pencatatan data pemakaian air telah dirancang dan direalisasikan menggunakan Wemos D1 Mini, selenoid valve, smartphone Android, dan koneksi WiFi. Selenoid valve digunakan agar saat terjadi kerusakan pada perangkat water meter maka aliran air akan berhenti sehingga tidak terjadi kerugian karena penggunaan air yang tidak terhitung oleh perangkat water meter. Koneksi WiFi digunakan untuk komunikasi data antara Wemos D1 Mini 
dan smartphone Android. Data pemakaian air disimpan pada SQLite database di smartphone Android, yang nantinya akan diproses di kantor perusahaan air untuk membuat tagihan biaya penggunaan air kepada pelanggan.

\section{LANDASAN TEORI}

A. Sensor Aliran

Sensor aliran yaitu perangkat yang dapat mengukur aliran dari suatu fluida baik sludge, liquid, maupun gas yang memiliki temperatur rendah hingga temperature tinggi. Sensor aliran memiliki beberapa tipe yaitu:

- Volumetric : flow sensor yang memiliki keluaran sinyal berdasarkan jumlah volume yang melewati sensor.

- Mass : flow sensor yang memiliki keluaran sinyal berdasarkan massa yang melewati sensor.

- Velocity : flow sensor yang memiliki keluaran sinyal berdasarkan kecepatan yang melewati sensor.

Sensor aliran air yang digunakan pada penelitian ini yaitu sensor aliran air G1/2 (Gambar 1). Sensor aliran air G1/2 adalah sensor aliran air yang menggunakan hall-effect. Sensor aliran terdiri dari rotor air, sensor hall-effect dan tubuh katup plastik.

Penelitian-penelitian sebelumnya yang menggunakan sensor aliran air G1/2 yaitu Yaddarabullah dan Dewi Lestari [8] menggunakan sensor aliran air G1/2 pada alat pencatatan meter air PDAM. Graha DS dkk [6] menggunakan sensor aliran air G1/2 untuk mendeteksi kebocoran kran air. Herdianto dkk [7] menggunakan sensor aliran air G1/2 untuk sistem meteran air pelanggan.

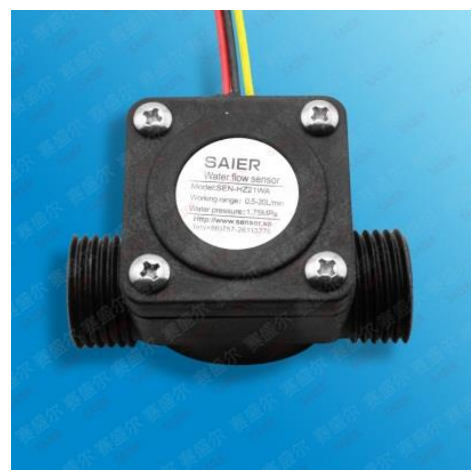

Gambar 1. Sensor Aliran G1/2

Perhitungan debit didapat dari karakteristik sensor yaitu dengan mencari terlebih dahulu frekuensi dari sinyal pulsa lalu dibagi dengan faktor kalibrasi sehingga didapat nilai debit [8].

Debit $=\frac{1000.0 \times \text { Frekuensi Pulsa }}{\text { faktor kalibrasi }}(L /$ menit $)$
Volume $=\frac{\text { Debit }}{60} \times 1000(L)$

\section{B. ESP8266}

ESP8266 (Gambar 2) adalah WiFi SOC (System on a chip) yang diproduksi oleh Espressif Systems. ESP8266 adalah chip yang terintegrasi dan dirancang untuk menyediakan konektivitas internet dalam paket kecil.

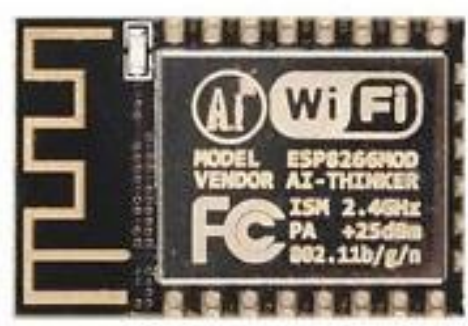

Gambar 2. ESP8266

ESP8266 dapat digunakan sebagai modul WiFi eksternal, menggunakan standar AT Command dengan menghubungkannya ke mikrokontroler, setiap menggunakan serial UART, atau langsung berfungsi sebagai pengendali mikro WiFi-enabled, dengan pemrograman firmware baru menggunakan SDK yang disediakan. Pin GPIO pada ESP8266 memungkinkan input dan output analog dan digital, ditambah PWM, SPI, I2C, dll.

Board Wemos D1 Mini berbasis ESP8266 digunakan pada penelitian ini. Board Wemos D1 Mini berbasis ESP8266 (Gambar 3) merupakan pengembangan yang didasarkan pada modul ESP8266 seri 12 untuk mempermudah proses pemrograman karena board ini mendukung Arduino IDE. Wemos D1 Mini memiliki 11 digital input/output dan 1 analog input.

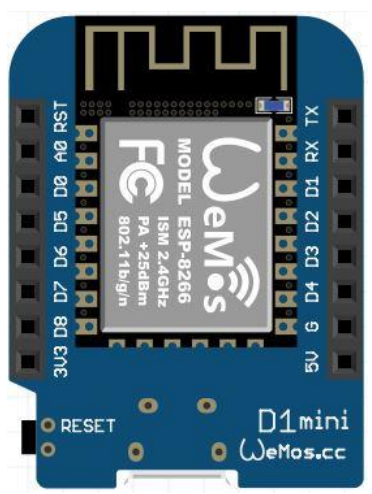

Gambar 3. Wemos D1 Mini 


\section{Solenoid Valve}

Solenoid Valve yaitu katup yang dapat dibuka atau ditutup dengan menggunakan aliran listrik. Solenoid valve yang digunakan pada penelitian ini (Gambar 4) yaitu jenis normally close. Dengan menggunakan selenoide valve jenis normally close maka ketika tidak ada daya listrik maka aliran air akan terhenti, sehingga tidak akan merugikan bagi perusahaan penyedia air akibat aliran air yang tidak terhitung.

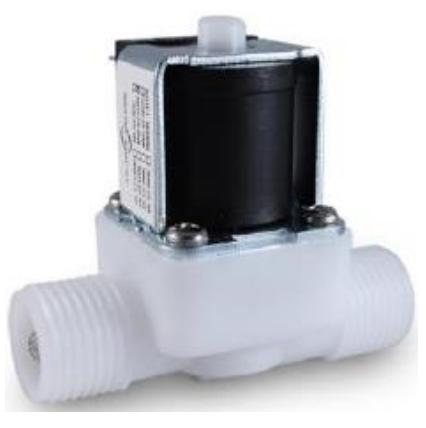

Gambar 4. Selenoide Valve

\section{Modul 4-Bit LED Digital Tube}

Pada penelitian ini modul 4-bit LED digital tube digunakan untuk menampilkan data penggunaan air. Modul 4-Bit LED digital tube (Gambar 5) menggunakan penggabungan shift register 74595 dengan sevent segment 4 digit. Modul ini hanya membutuhkan tiga koneksi untuk menyalakan 4-digit seven segment yaitu SCLK, RCLK, dan DIO.
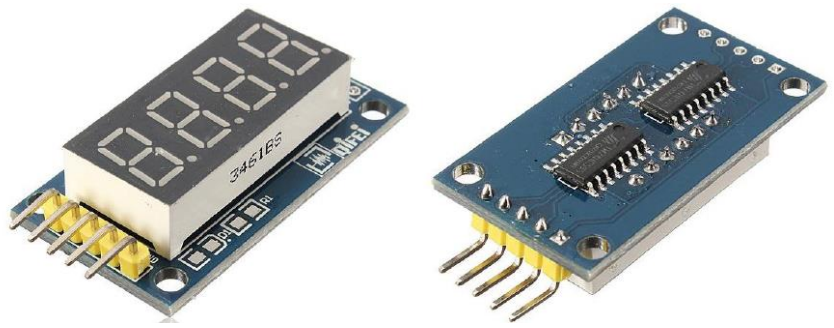

Gambar 5. Modul Display 4-Bit LED Digital Tube

\section{E. Arduino}

Arduino yaitu sebuah open source platform yang digunakan untuk membuat berbagai perangkat elektronika berbasis mikrokontroler. Arduino platform terdiri dari dua bagian utama yaitu perangkat keras (board) dan perangkat lunak. Perangkat lunak ini sering disebut juga sebagai Arduino IDE yang digunakan untuk menulis dan memasukan kode dari komputer ke perangkat keras (board) Arduino [9]. Pada penelitian ini, program untuk board Wemos D1 Mini dibuat menggunakan perangkat lunak Arduino.
F. Android

Android yaitu sistem operasi berbasis Linux yang dirancang untuk perangkat mobile seperti tablet PC dan smartphone. Sistem operasi ini dikeluarkan secara resmi pada tahun 2007, bersamaan dengan didirikannya Open Handset Alliance (OHA), konsorsium dari perusahaanperusahaan perangkat lunak, perangkat keras dan telekomunikasi yang bertujuan untuk memajukan standar terbuka perangkat seluler. Ponsel Android pertama mulai dijual pada bulan Oktober 2008 [10]. Android Sofware Development Kit (SDK) menyediakan tools dan Application Programming Interface (API) yang diperlukan untuk mengembangkan program pada Android platform dengan menggunakan bahasa java. Linux digunakan sebagai basis sistem operasi Android. Sistem operasi Android merupakan kumpulan komponen perangkat lunak yang berbentuk stack yang dibagi kedalam 4-layer dan 5 bagian utama (Gambar 6), yaitu:

- Applications yaitu layer yang berhubungan dengan aplikasi, misalnya: sms, email, peta, kalender, kontak, browser, dll.

- Applications Frameworks yaitu layer untuk melakukan pembuatan aplikasi yang akan dijalankan di sistem operasi Android.

- Libraries yaitu layer yang berisi fitur-fitur Android.

- Android Run Time, aplikasi Android dapat dijalankan pada layer ini.

- Linux Kernel yaitu layer inti dari sistem operasi Android yang berisi file-file system yang mengatur sistem processing, memori, driver, resource dan sistem operasi Android lainnya.

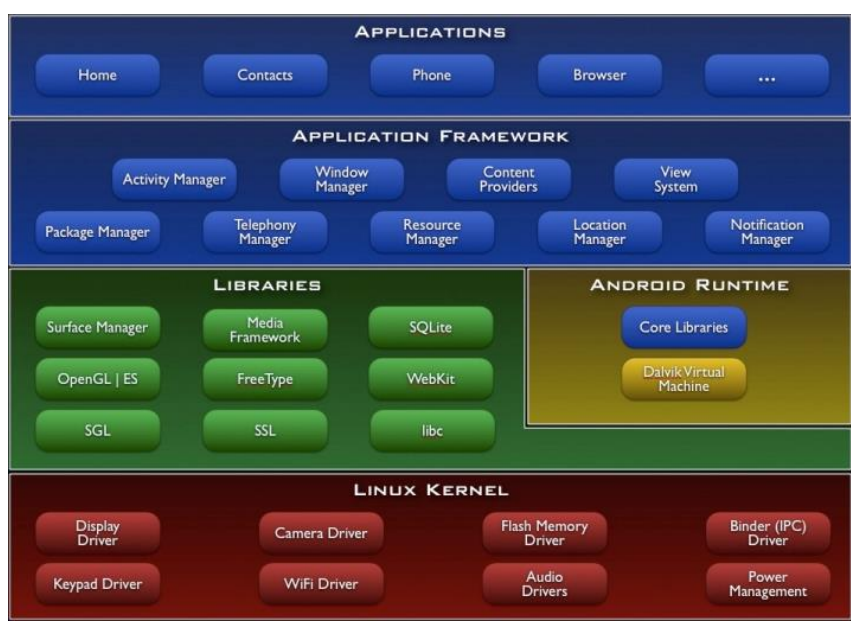

Gambar 6 Arsitektur Android

Pada penelitian ini, aplikasi pada smartphone Android dibuat menggunakan Android Studio yang merupakan Integrated Development Environment (IDE) untuk 
pengembangan program Android [11], selain merupakan alat pengembang yang berdaya guna dan editor kode IntelliJ, Android Studio menawarkan fitur lebih banyak untuk meningkatkan produktivitas saat membuat program Android, misalnya:

- Emulator yang kaya fitur dan cepat

- Sistem versi berbasis Gradle yang fleksibel

- Lingkungan yang menyatu untuk pengembangan bagi semua perangkat Android

- Instant Run untuk mendorong perubahan ke aplikasi yang berjalan tanpa membuat APK baru

- Template kode program dan integrasi GitHub untuk membuat fitur aplikasi yang sama dan mengimpor kode contoh

- Kerangka kerja yang ekstensif dan alat pengujian

- Alat Lint untuk kegunaan, kompatibilitas versi, meningkatkan kinerja, dan masalah-masalah lain

- Dukungan NDK dan C++

- Mempermudah pengintegrasian Google Cloud Messaging dan App Engine, dukungan bawaan untuk Google Cloud Platform.

\section{Metodologi PENELITIAN}

Pada penelitian ini, metode penelitian yang digunakan terdiri dari lima tahap (Gambar 7). Tahap pertama yaitu merancang sistem pencatatan penggunaan air berbasis smartphone Android. Tahap kedua yaitu merancang dan membuat perangkat water meter (perangkat keras dan perangkat lunak untuk water meter). Tahap ketiga yaitu merancang dan membuat perangkat lunak untuk smartphone Android. Tahap keempat yaitu pengujian perangkat water meter dan aplikasi pada smartphone yang terdiri dari pengujian faktor kalibrasi, pengujian akurasi dan pengujian jarak jangkauan komunikasi antara perangkat water meter dengan aplikasi pada smartphone. Tahap kelima yaitu evaluasi kinerja sistem keseluruhan.

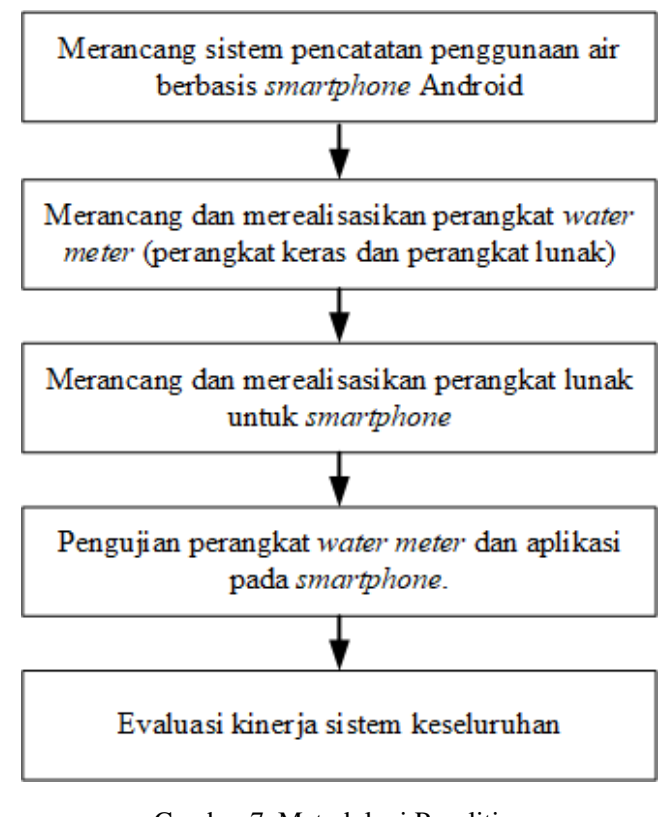

Gambar 7. Metodologi Penelitian

\section{DESAIN SISTEM}

Pada bagian ini dijelaskan mengenai perancangan dan realisasi perangkat keras serta perancangan dan realisasi perangkat perangkat lunak, untuk sistem pencatatan penggunaan air. Perangkat keras meliputi wiring diagram rangkaian. Perangkat lunak meliputi diagram alir program pada Wemos D1 mini dan perangkat lunak smartphone Android meliputi antarmuka pada aplikasi serta diagram alir program Android.

\section{A. Diagram Blok Sistem}

Cara kerja dari perangkat water meter berdasarkan diagram blok system (Gambar 8) yaitu solenoid valve normally close berfungsi menghentikan aliran air ketika perangkat water meter mengalami kerusakan atau ketika tidak ada daya listrik yang mengakibatkan perangkat water meter tidak dapat menghitung penggunaan air. Sensor aliran G1/2 mengirimkan sinyal yang berupa sinyal pulsa yang akan diterima oleh Wemos yang kemudian akan diproses sebagai data penggunaan air, selanjutnya data penggunaan air ditampilkan pada modul seven segment dalam satuan liter. Data penggunaan air juga akan dikirim ke smartphone melalui koneksi WiFi jika ada permintaan dari smartphone. Data yang diterima oleh smartphone kemudian disimpan pada database lokal di smartphone, untuk keperluan selanjutnya database yang disimpan pada smartphone ini dapat dipindahkan ke komputer. 


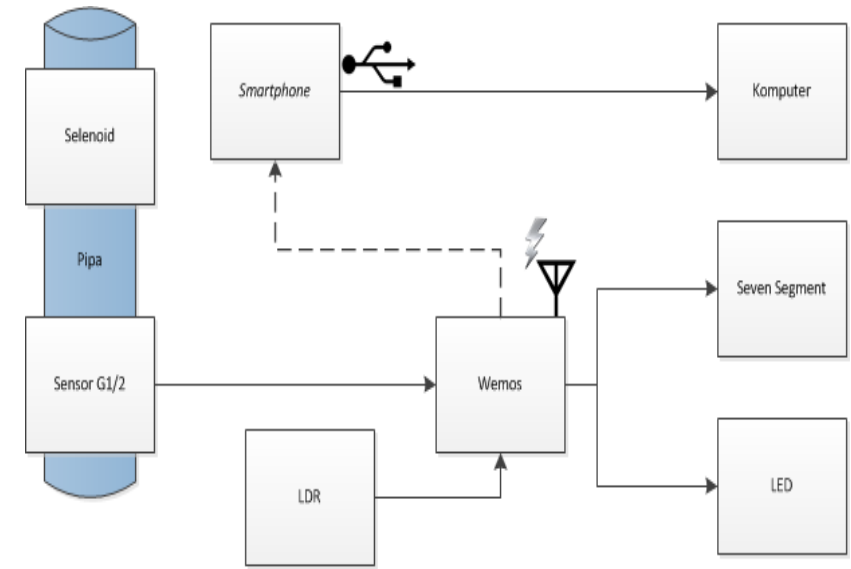

Gambar 8. Diagram Blok Sistem

\section{B. Perancangan Perangkat Keras}

Pada bagian ini akan dijelaskan perancangan perangkat keras yaitu wiring diagram rangkaian. Perangkat keras dirancang untuk keperluan pengambilan data penggunaan air dalam rangka untuk mempermudah pengambilan data penggunaan air pada setiap pelanggan. Wiring diagram (Gambar 9) menunjukkan komponen-komponen yang digunakan dan hubungan antara komponen-komponen yang digunakan (Tabel I).

Terdapat beberapa komponen yaitu sensor aliran air, solenoid valve, 4 Bit LED Digital Tube Module, relay, regulator $5 \mathrm{~V}$, baterai $12 \mathrm{~V}$, LDR, LED indikator dan konektor daya utama. Beberapa komponen penunjang lainnya yaitu relay, regulator $5 \mathrm{~V}$, baterai, LED indikator sensor, dan LDR. LDR berfungsi sebagai saklar bagi Wifi sehingga saat siang hari Wifi aktif dan malam hari Wifi tidak aktif. LED berfungsi sebagai indikator sensor yaitu sebagai indikator untuk mengetahui apakah sensor aliran dapat bekerja dengan baik dengan cara memanfaatkan sinyal keluaran dari sensor yang berupa sinyal pulsa, sinyal pulsa ini dihubungkan dengan LED yang mengakibatkan LED akan menyala secara berkedip sehingga dari kedipan ini dapat diketahui bahwa baling baling yang ada pada sensor aliran bekerja dengan baik.

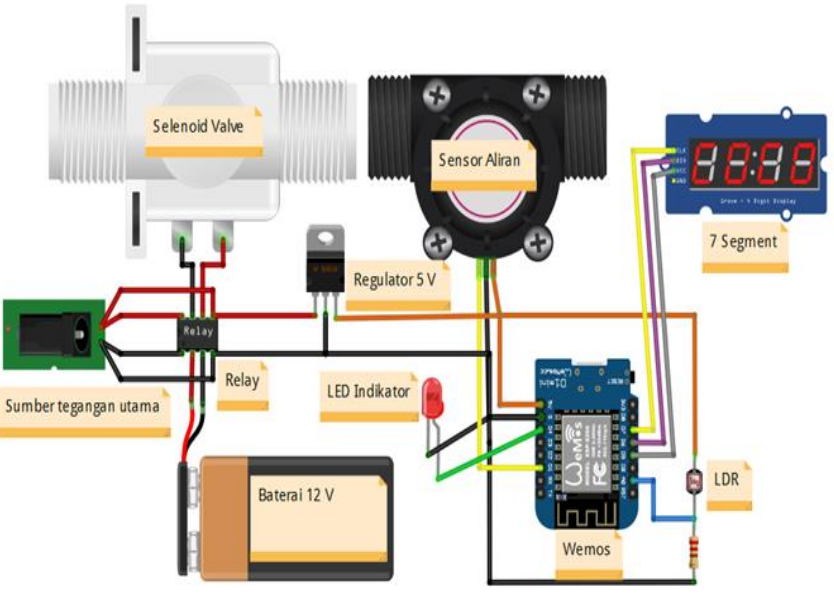

Gambar 9 Wiring Diagram Perangkat Water Meter

TABEL I

HUBUNGAN ANTARA KOMPONEN

\begin{tabular}{|c|l|}
\hline Pin Wemos & \multicolumn{1}{|c|}{ Komponen } \\
\hline 5V & Sumber Tegangan (+) \\
\hline G & Sumber Tegangan (-) \\
\hline A0 & Output LDR \\
\hline D1 & Output Flow Sensor \\
\hline D4 & LED Indikator Sensor \\
\hline D5 & SCLK \\
\hline D6 & RCLK \\
\hline D7 & DIO \\
\hline &
\end{tabular}

\section{Perancangan Perangkat Lunak Water Meter}

Pada bagian ini akan dijelaskan perancangan perangkat lunak pada perangkat water meter (Gambar 10). Pertamatama pada saat dinyalakan maka daya akan mencatu solenoid valve yang selanjutnya akan membuat valve terbuka sehingga air dapat mengalir, jika suplai daya utama tidak dapat mencatu solenoid valve, maka daya baterai yang akan mencatu solenoid valve agar dapat terbuka untuk sementara waktu. Perhitungan debit didapat setelah mendapat nilai frekuensi pulsa yang dihasilkan sensor dibagi faktor kalibrasi.

Data yang telah dihitung oleh sensor flow dengan perhitungan rumus yang didapat dari datasheet sensor sehingga diperoleh nilai penggunaan air dalam satuan liter yang ditampilkan oleh modul seven segment, selanjutnya data ini akan dikirimkan oleh perangkat water meter ke smartphone Android jika ada permintaan dari smartphone. 

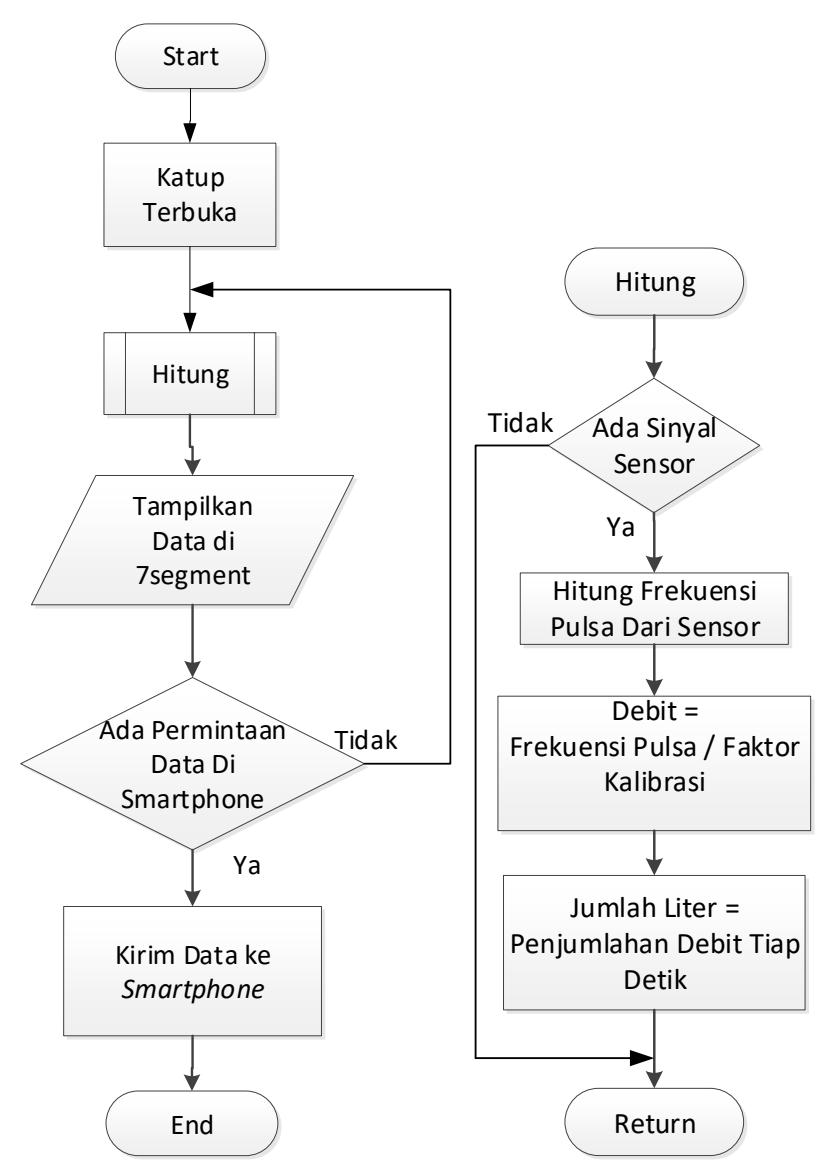

Gambar 10 Flowchart Program pada Perangkat Water Meter

Kode Program 1 adalah potongan program Arduino untuk menghitung penggunaan air. Proses perhitungan ini dilakukan sekali per detik.

Kode Program 1 Menghitung Penggunaan Air

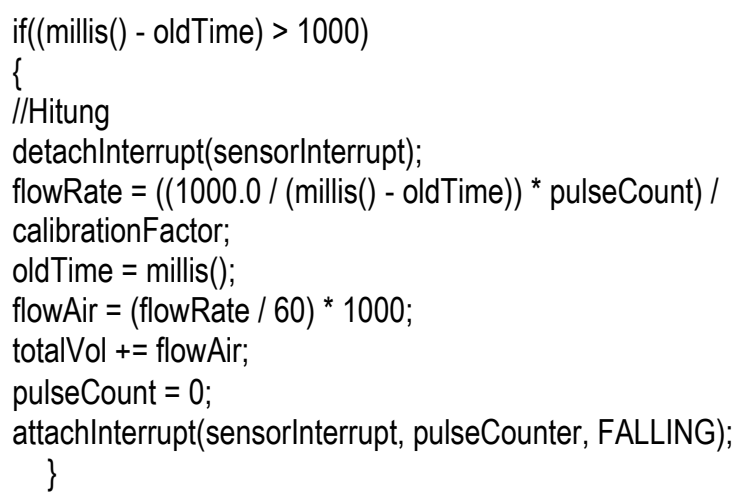

Kode Program 2 adalah potongan kode Arduino untuk menampilkan data ke modul seven segment (modul 4-bit LED digital tube).
Kode Program 2 Menampilkan Data ke Modul Seven Segment.

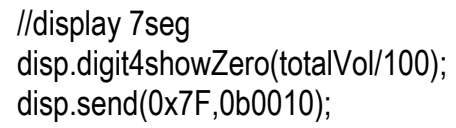

Kode Program 3 adalah potongan program Arduino untuk menerima data dari smartphone, yang berisi permintaan agar perangkat water meter mengirimkan data jumlah pemakaian air ke smatphone Android, kemudian perangkat water meter akan mengirimkan data pemakaian air ke smartphone.

Kode Program 3 Menerima Data dari Smartphone

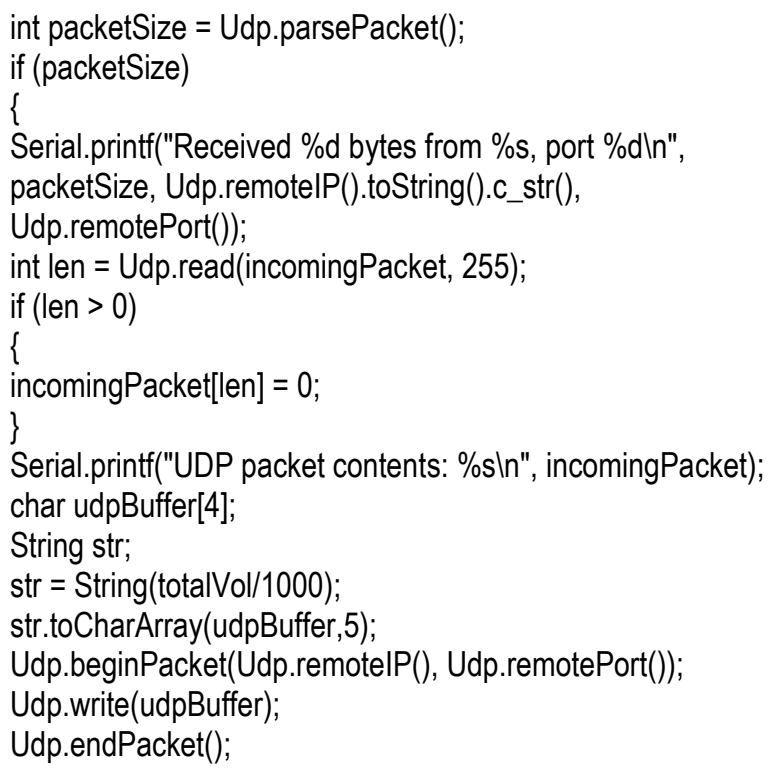

D. Perancangan Perangkat Lunak Smartphone

Pada bagian ini akan dijelaskan perancangan perangkat lunak yaitu diagram alir untuk program Android pada smartphone (Gambar 11) dan perancangan GUI (Gambar 12). Program aplikasi untuk Smartphone Android dibuat menggunakan perangkat lunak Android Studio, untuk dapat dipasang pada smartphone Android maka program ini kemudian dibangun sehingga menjadi file yang memiliki ekstensi APK (Android Package File). File APK ini adalah file yang dapat dipasang pada smartphone yang memiliki sistem operasi Android. Cara kerja program pada smartphone yaitu pada saat program dimulai pada smartphone maka smartphone akan menampilkan database pelanggan yang telah ada sebagai tampilan awal, kemudian petugas memilih salah satu data pelanggan untuk mengambil data penggunaan air oleh pelanggan tersebut. Permintaan pengambilan data pemakaian air akan dikirim melalui koneksi WiFi sehingga diperlukan koneksi WiFi antara smartphone dan perangkat water meter. Data yang 
telah diterima oleh smartphone selanjutnya akan dimasukkan sesuai dengan identitas pelanggan. Pengambilan data pengguna dilakukan bila koneksi dengan alat sudah terhubung dan data yang diambil sudah sesuai antara identitas perangkat pencatat penggunaan air dan identitas pelanggan yang ada pada smartphone.

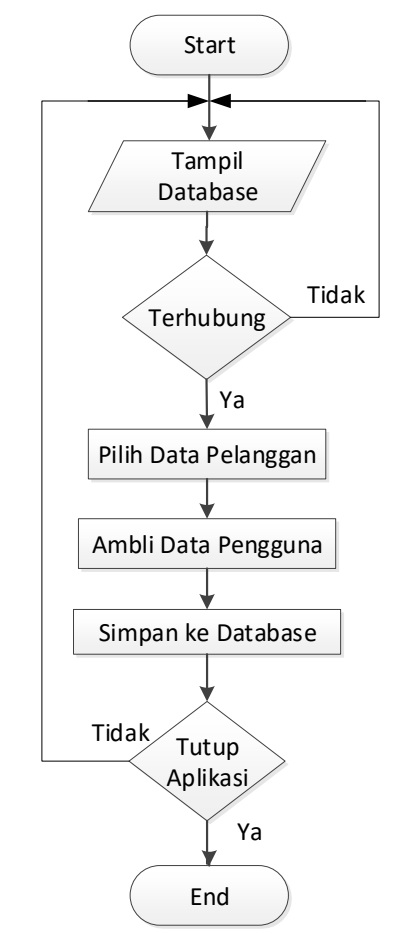

Gambar 11 Flowchart Perangkat Lunak

\section{E. Perancangan GUI Smartphone}

Perancangan GUI untuk program pada smartphone yang terdiri dari penempatan komponen-komponen yang digunakan ditunjukan pada Gambar 12 dan Gambar 13. Penjelasan fungsi-fungsi dari setiap komponen yang digunakan dapat dilihat pada Tabel II.

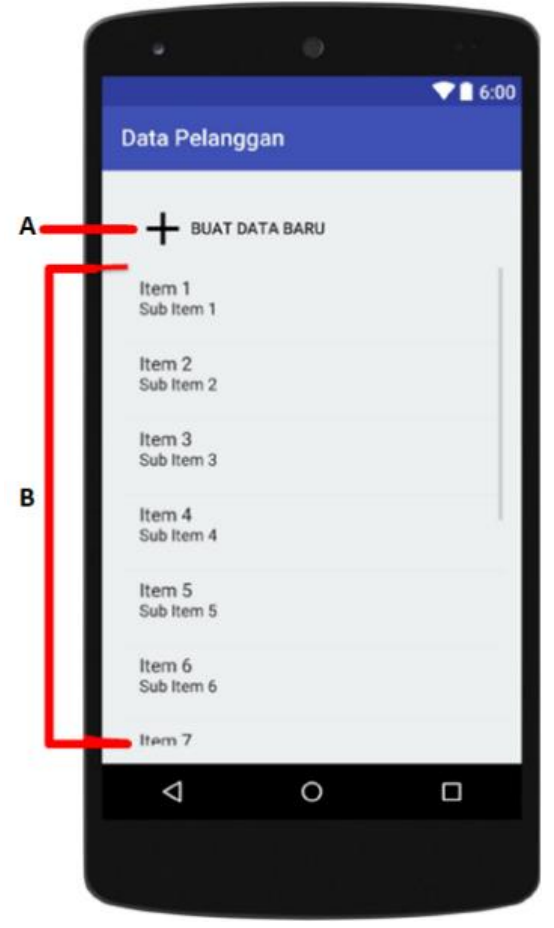

Gambar 12 Perancangan GUI Menambahkan Pelanggan

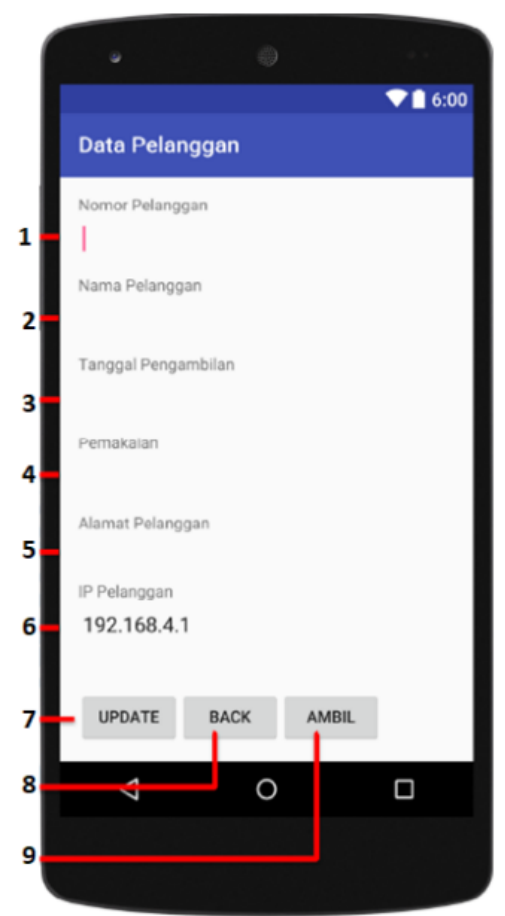

Gambar 13 Perancangan GUI Memasukan Data Pelanggan

Dari Gambar 12 terdapat beberapa komponen yang telah ditandai dengan angka dan huruf pada setiap komponen yang digunakan untuk merancang GUI pada smartphone. Setiap komponen memiliki fungsi berbeda beda yang akan dijelaskan pada Tabel II. 
TABEL II

KOMPONEN YANG DIGUNAKAN DALAM RANCANGAN GUI

\begin{tabular}{|l|l|l|}
\hline No & $\begin{array}{l}\text { Nama } \\
\text { Komponen }\end{array}$ & Fungsi \\
\hline A & Button & Menambahkan data pelanggan baru \\
\hline B & List View & Daftar nama pelanggan yang terdaftar \\
\hline 1 & Edit Text & Input no pelanggan \\
\hline 2 & Edit Text & Input nama pelanggan \\
\hline 3 & Edit Text & Input tanggal \\
\hline 4 & Edit Text & Input pemakaian air \\
\hline 5 & Edit Text & Input alamat pelangga \\
\hline 6 & Edit Text & Input IP pelanggan \\
\hline 7 & Button & Menyimpan data pelanggan \\
\hline 8 & Button & Kembali tanpa melakukan perubahan \\
\hline 9 & Button & Mengambil data pemakaian \\
\hline
\end{tabular}

Kode Program 4 adalah potongan program Android untuk mengirimkan data ke perangkat water meter:

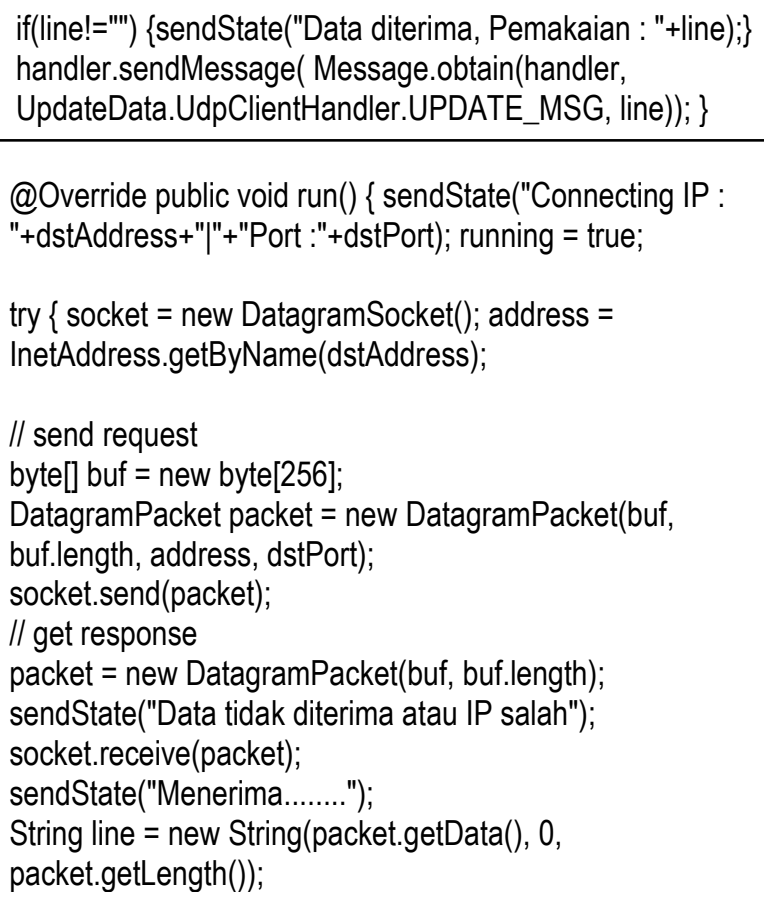

Kode Program 4 Mengirimkan Data ke Perangkat

Kode Program 5 adalah potongan program Android untuk menyimpan data penggunaan air ke dalam database SQLite.
Kode Program 5 Menyimpan Data Penggunaan Air ke Database

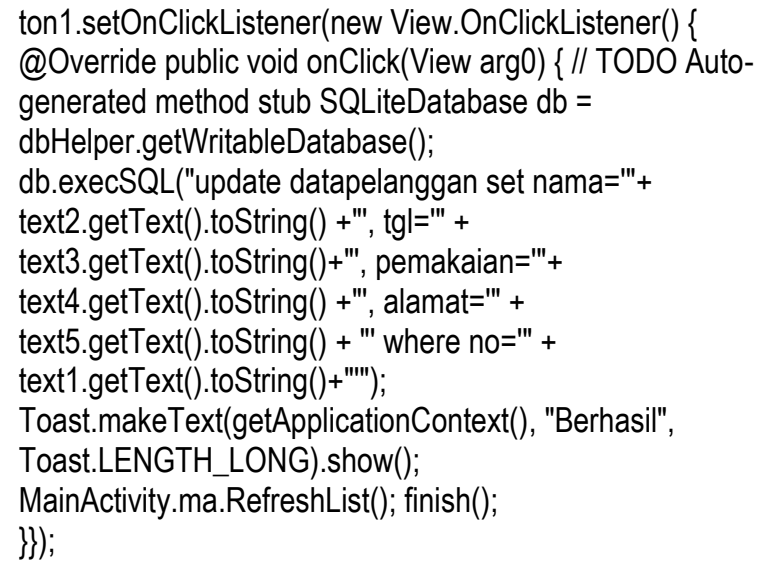

\section{IMPLEMENTASI SISTEM}

Realisasi sistem keseluruhan terdiri dari 2 bagian yaitu realisasi sistem perangkat keras water meter, dan realisasi aplikasi di smartphone Android.

\section{A. Realisasi perangkat water meter}

Pada realisasi perangkat water meter (Gambar 14) terdapat dua alat terhubung melalui pipa yaitu solenoid valve dan sensor aliran, pemasangan dilakukan dengan cara solenoid valve dipasang pada bagian depan lalu dilanjutkan oleh sensor aliran.

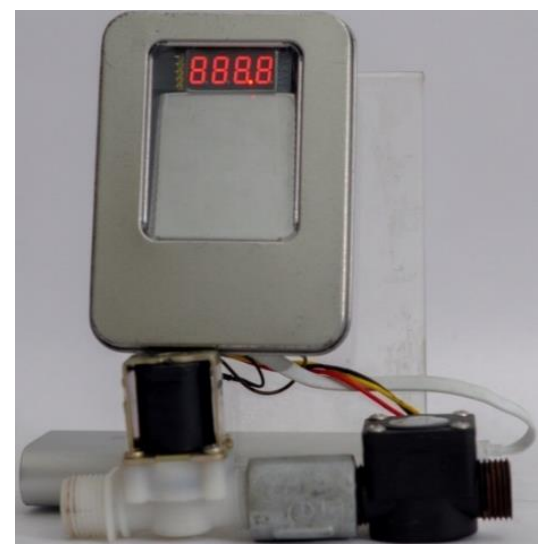

Gambar 14 Realisasi Perangkat Keras Water Meter

Realisasi perangkat menggunakan kotak yang berisi komponen-komponen yang sensitif terhadap air sehingga komponen tersebut dapat terlindungi oleh kotak yang kedap terhadap air. 
B. Realisasi program aplikasi di smartphone

Program aplikasi pada smartphone disini ditujukkan untuk menampilkan database pelanggan yang sudah terdaftar sebelumnya dan dapat membuat data pelanggan baru. Gambar 15 menampilkan GUI pada saat tampilan awal yang menampilkan nama pelanggan yang sudah terdaftar sebelumnya.

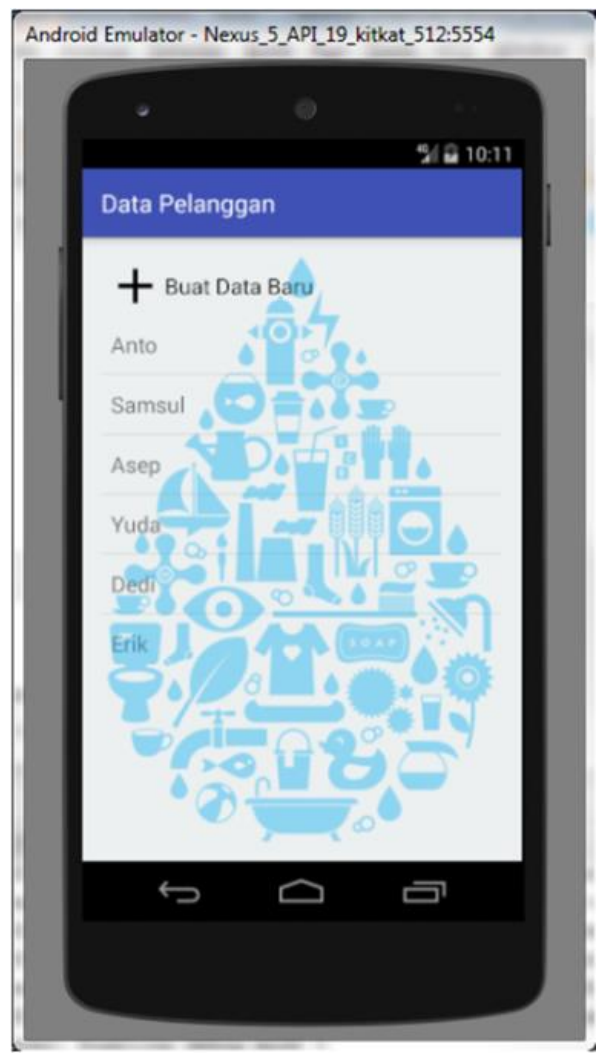

Gambar 15 Realisasi aplikasi di smartphone Android

\section{HASIL PENGUJIAN}

\section{A. Pengujian Faktor Kalibrasi}

Pada bagian ini akan dijelaskan pengujian nilai faktor kalibrasi dengan metode trial and error agar didapatkan hasil dengan error yang terkecil, sehingga perangkat water meter dapat menghitung penggunaan air yang mendekati nilai penggunaan air yang sebenarnya.

Nilai faktor kalibrasi yang dicoba menggunakan metoda trial and error berkisar antara 4.2 sampai dengan 10. Nilai factor kalibrasi 10 merupakan nilai factor kalibrasi yang menghasilkan pembacaan nilai volume air sebenarnya, sehingga metode trial and error selanjutnya dilakukan dengan menggunakan nilai 10.2, 10.3, dan 10.4.
TABEL III

PEGUJIAN FAKTOR KALIBRASI

\begin{tabular}{|c|r|r|r|}
\hline \multirow{2}{*}{$\begin{array}{c}\text { Liter } \\
\text { Konvensional }\end{array}$} & \multicolumn{3}{|c|}{ Faktor Kalibrasi } \\
\cline { 2 - 4 } & $\mathbf{1 0 . 2}$ & $\mathbf{1 0 . 3}$ & \multicolumn{1}{c|}{$\mathbf{1 0 . 4}$} \\
\hline 1 & 1.058 & 0.973 & 0.935 \\
\hline 5 & 5.028 & 5.000 & 4.994 \\
\hline 10 & 10.093 & 10.032 & 9.920 \\
\hline 20 & 20.039 & 20.091 & 19.870 \\
\hline 35 & 35.464 & 35.170 & 34.839 \\
\hline 50 & 50.723 & 50.243 & 49.733 \\
\hline 75 & 76.196 & 75.374 & 74.711 \\
\hline 100 & 101.620 & 100.411 & 99.470 \\
\hline 150 & 152.706 & 150.720 & 149.319 \\
\hline 200 & 203.786 & 200.869 & 199.045 \\
\hline Error Rata rata & 1.0713 & 0.2937 & 0.3164 \\
\hline
\end{tabular}

Dari Tabel III didapatkan bahwa faktor kalibrasi sebesar 10.3 memiliki nilai error terkecil sehingga faktor kalibrasi 10.3 digunakan untuk mengitung jumlah pemakaian air pada program Arduino yang akan dimasukan ke perangkat water meter.

\section{B. Pengujian Akurasi}

Setelah faktor kalibrasi ditentukan, langkah selanjutnya yaitu pengujian akurasi perhitungan penggunaan air yang dilakukan oleh perangkat, kemudian hasil perhitungan oleh perangkat water meter dibandingkan dengan meteran air konvensional. Hasil pengujian akurasi dapat dilihat pada Tabel IV. Dari Tabel IV didapatkan rata-rata error pembacaan sebesar 0,2937. Error masing-masing pengujian didapatkan dari harga mutlak nilai pembacaan oleh perangkat dikurangi oleh nilai pembacaan oleh meteran konvensional.

TABEL IV

PENGUJIAN AKURASI

\begin{tabular}{|c|r|c|}
\hline $\begin{array}{c}\text { Meteran air } \\
\text { konvensional (Liter) }\end{array}$ & $\begin{array}{c}\text { Perangkat } \\
\text { (Liter) }\end{array}$ \\
\hline 1 & 0.973 & 0,027 \\
\hline 5 & 5.000 & 0,000 \\
\hline 10 & 10.032 & 0.032 \\
\hline 20 & 20.091 & 0.091 \\
\hline 35 & 35.170 & 0.170 \\
\hline 50 & 50.243 & 0.243 \\
\hline 75 & 75.374 & 0.374 \\
\hline
\end{tabular}




\begin{tabular}{|c|r|r|}
\hline $\begin{array}{c}\text { Meteran air } \\
\text { konvensional (Liter) }\end{array}$ & $\begin{array}{c}\text { Perangkat } \\
\text { (Liter) }\end{array}$ & Error \\
\hline 100 & 100.411 & 0.411 \\
\hline 150 & 150.720 & 0.720 \\
\hline 200 & 200.869 & 0.869 \\
\hline
\end{tabular}

\section{Pengujian Jarak Jangkauan}

Pada pengujian jarak jangkauan komunikasi antara perangkat water meter dan smartphone ini dilakukan pada dua kondisi yaitu ketika ada halangan berupa tembok dan tanpa halangan. Hasil pengujian jarak jangkauan komunikasi antara perangkat water meter dan smartphone dapat dilihat pada Tabel V dan Tabel VI.

TABEL V

PENGUJIAN JARAK TANPA HALANGAN

\begin{tabular}{|c|c|}
\hline Jarak(m) & Penerimaan data \\
\hline 1 & Berhasil diterima \\
\hline 5 & Berhasil diterima \\
\hline 10 & Berhasil diterima \\
\hline 15 & Berhasil diterima \\
\hline 20 & Berhasil diterima \\
\hline 25 & Berhasil diterima \\
\hline 30 & Berhasil diterima \\
\hline 35 & Berhasil diterima \\
\hline 37 & Berhasil diterima \\
\hline 38 & Gagal diterima \\
\hline
\end{tabular}

Dari Tabel V didapatkan jarak jangkauan komunikasi antara perangkat water meter dan smartphone Android tanpa halangan mencapai 37 meter.

TABEL VI

PENGUJIAN JARAK JANGKAUAN DENGAN HALANGAN

\begin{tabular}{|c|c|}
\hline Jarak(m) & Penerimaan data \\
\hline 1 & Berhasil diterima \\
\hline 2 & Berhasil diterima \\
\hline 3 & Berhasil diterima \\
\hline 5 & Berhasil diterima \\
\hline 7 & Berhasil diterima \\
\hline 9 & Berhasil diterima \\
\hline 11 & Berhasil diterima \\
\hline 13 & Berhasil diterima \\
\hline
\end{tabular}

\begin{tabular}{|c|c|}
\hline Jarak(m) & Penerimaan data \\
\hline 15 & Berhasil diterima \\
\hline 16 & Gagal diterima \\
\hline
\end{tabular}

Dari Tabel VI didapatkan jarak jangkauan komunikasi antara perangkat water meter dan smartphone Android dengan halangan berupa tembok mencapai 15 meter.

\section{KESIMPULAN}

Sistem pencatatan penggunaan air berbasis smartphone Android yang terdiri dari perangkat water meter dan aplikasi pada smartphone Android telah berhasil dirancang dan direalisasikan serta dapat menghitung pemakaian air dengan baik. Data yang dikirim perangkat water meter ke smartphone dapat diterima melalui koneksi WiFi hingga jarak 37-meter tanpa halangan dan 16-meter dengan halangan.

\section{SARAN}

Untuk pengembangan sistem pencatatan penggunaan air selanjutnya yaitu setiap perangkat water meter yang berada pada rumah-rumah pelangan dapat terkoneksi dengan internet sehingga perangkat water meter akan mengirim data melalui internet. Selain itu, fasilitas membuka dan menutup aliran air serta menghitung aliran air dapat dibuat dalam satu perangkat water meter sehingga lebih efisien.

\section{DAFTAR PUSTAKA}

[1] Lam KL, Tung HY, Lee LT, Tsang KF, "ZigBee Automatic Meter Reading System - Beeline of Metering," Asia Pacific Microwave Conference, 2008, pp. 0-3.

[2] Anwar C, Hardiyan. "Analisa Penggunaan Aplikasi Android Meter Reading PDAM Terhadap Kepuasan Pelanggan," Paradigma, vol. 20, no.1, pp.48-52, 2018.

[3] Gokilapriya V, Bhuvaneswari PT V, "Design and Development of SoC Based Residential Water Meter Monitoring System," International Conference on Wireless Communications, Signal Processing and Networking (WiSPNET), 2017, pp. 2163-2166.

[4] Botha S, Meijsen LA, Hancke GP, Silva BJ, "Design of a water flow and usage meter," IECON 2016 - 42nd Annual Conference of the IEEE Industrial Electronics Society, 2016, pp. 6211-6215.

[5] Cherukutota N, Jadhav S, "Architectural Framework of Smart Water Meter Reading System In IoT Environment," International Conference on Communication and Signal Processing (ICCSP), 2016, pp. 791-794.

[6] Graha DS, Fathoni R, Hasad A, Paronda AH, "Sistem Proteksi Kebocoran Kran Dan Pencatatan Meteran Air Digital Pada PDAM Berbasis Mikrokontroller Arduino Uno R3," JREC (Journal of Electrical and Electronics), vol. 5, no. 1, pp.21-32, 2017.

[7] Herdianto, Sebayang AN, Nasution D, "Sistem Monitoring Data Meteran air pelanggan PDAM menggunakan mikrokontroler ATmega 16," KOMIK (Konferensi Nasional Teknologi Informasi dan Komputer, 2017, vol.1, no.1,pp.33-39..

[8] Yaddarabullah, Lestari D, "Perancangan Sistem Komunikasi 
Data Alat Pencatatan Meter Air Digital Berbasis Service Oriented Architecture," InfoTekJar, vol.3, no.1, pp.49-54, 2018.

[9] Andrianto H, Darmawan A, Ardunio Belajar Cepat dan Pemrograman. Bandung: Informatika, 2016.

[10] Safaat HN, ANDROID Pemrograman Aplikasi Mobile Smartphone dan Tablet PC Berbasis Android. Edisi Revi.
Bandung: Informatika, 2012.

[11] Tanuwijaya E, "Rancang Bangun Aplikasi Penitipan Hewan Peliharaan Berbasis Android," Jurnal Teknik Informatika dan Sistem Informasi, vol.4, no.3, pp.365-75, 2018. 